\title{
La labor del pediatra para prevenir que los derechos de niñas, niños y adolescentes sean vulnerados
}

\author{
The role of pediatricians to \\ prevent the violation of children \\ and adolescents' rights.
}

La Organización de las Naciones Unidas distinguió que el 20 de noviembre de cada año se reconozca el Día Universal del Niño. Esta decisión fue tomada en 1989, cuando se firmó la Convención de los Derechos del Niño en un compromiso para garantizar su cumplimiento. México ratificó esta convención en 1990. En este convenio se establecen una serie de derechos para las niñas, niños y adolescentes de todo el mundo, los cuales consideran la vida, la salud, la educación y el juego, así como el derecho a vivir en familia, a estar protegidos contra toda forma de violencia, a no ser discriminados y a que sus opiniones sean escuchadas.

El 10 de junio de 2011, en México, se estableció la paridad de los derechos humanos ya previstos en la Constitución de los Estados Unidos Mexicanos con los tratados internacionales de los cuales el Estado Mexicano es parte, con todo lo que ello implica. Estas reformas constitucionales "generan la impostergable necesidad de profundizar en el estudio de los tratados internacionales que reconocen los derechos humanos y en las que el Estado Mexicano es parte".

Como todos los servidores públicos, los médicos y personal de salud que trabajamos en instituciones del sector público formamos parte del Estado y tenemos la obligación de fomentar y cumplir dichos derechos.

Desde el ámbito de la salud, quienes nos encontramos involucrados en su quehacer tenemos la gran responsabilidad de fomentar y vigilar que se cumplan los derechos humanos de las niñas, niños y los adolescentes. De esta manera, debemos centrar nuestra atención, como educadores y formadores, en orientar y ayudar a nuestros pacientes a desarrollar un sentido de responsabilidad y espíritu emprendedor, así como un compromiso en la solución de sus necesidades 
de salud. Es decir, inculcar y fomentar acciones de autocuidado, que refuercen sus valores, así como sus habilidades y capacidades para generar en ellos cambios de actitudes, hábitos y conductas que les permitan madurar y contribuyan a que sean responsables de su salud en la vida adulta.

Una situación especial y de actualidad es poder trabajar en la prevención del embarazo adolescente; condición que no solamente vulnera los derechos de la futura madre, sino también los del producto en gestación, pues incrementa la transmisión de la pobreza y pone en riesgo la salud de la madre y su hijo. También afecta la continuidad y acceso a la educación en los padres, al modificar su proyecto de vida e incrementar el riesgo de abandonar sus estudios, lo que a su vez dificulta la obtención de un empleo que les permita desarrollarse plenamente. Esto socava las competencias y favorece la trasmisión intergeneracional de la pobreza, perpetuando la vulnerabilidad, marginación y desigualdad existente. Por lo tanto, nuestra labor como capacitadores de pacientes y adolescentes cuando asisten a los centros de atención médica dará mejores resultados, considerando que no es la falta de información ni el acceso a los métodos de anticoncepción lo que principalmente contribuye al problema, sino la escasa educación y capacitación.

Otra condición que debemos atender con celeridad es la prevención y, en su caso, la detección de la violencia familiar y el maltrato infantil. Sus consecuencias, además de manifestarse en la infancia y la adolescencia, persisten durante la vida adulta y tienen repercusiones en la salud física y mental, lo que a su vez incrementa el riesgo de la transmisión intergeneracional del maltrato infantil.

No atender adecuadamente las situaciones previamente descritas vulnera un número im- portante de los derechos de este grupo etario. Por lo tanto, insistimos que todo el personal médico y paramédico que atiende niñas, niños y adolescentes debe conocer la legislación vigente sobre los derechos humanos para fomentarlos y prevenir violaciones a los mismos hasta donde sea posible.

Este accionar puede y debe ser una herramienta importante si queremos favorecer el máximo desarrollo de sus capacidades genéticas, físicas e intelectuales. Para que estos niños, a quienes pertenece el futuro, puedan convertirse en adultos responsables y que al ejercer sus derechos, puedan respetar y fomentar los de los demás.

\section{LECTURAS RECOMENDADAS}

1. Organización de las Naciones Unidas, n.d. Día Universal del niño 20 de noviembre [online]. Disponible en: http:// www.un.org/es/events/childrenday/ [27 de septiembre de 2016].

2. Suprema Corte de Justicia de la Nación, 2012. Reformas Constitucionales en materia de Amparo y Derechos Humanos publicados en junio de 2011 (Relación de tratados internacionales de los que el Estado Mexicano es parte en los que se reconocen Derechos Humanos) [online]. Disponible en: http://www2.scjn.gob.mx/red/constitucion/inicio. html [27 de septiembre de 2016].

3. Casas Muñoz A, Loredo Abdalá A. ¿Por qué debemos conocer los derechos de niñas, niños y adolescentes? Acta Pediatr Mex. 2014;35:437-439.

4. Casas-Muñoz A. Conocer y ejercer los derechos de niñas, niños y adolescentes para respetarlos y educarlos con responsabilidad. En: Loredo-Abdalá. Maltrato Infantil: Gravedad y Prevención. México, Editor de Textos Mexicanos, México, 2016, pag. 265-278.

5. Sumano-Avendaño E. Embarazo Adolescente: problema creciente. En: Loredo-Abdalá. Maltrato Infantil: Gravedad y Prevención. México, Editor de Textos Mexicanos, México, 2016, pag. 223-263.

6. Loredo-Abdalá A, Casas-Muñoz A, Navarro-Ampudia $P$, Villanueva-Clift H., García-Carranza A. Maltrato infantil: Riesgo y prevención. Academia Mexicana de Pediatría. Medigraphic, México, 2015.

7. González-García N, Díaz-Santana RE. Alcances del maltrato psicológico en el desarrollo emocional de niñas, niños y adolescentes. En: Loredo-Abdalá. Maltrato Infantil: Gravedad y Prevención. México, Editor de Textos Mexicanos, México, 2016, pag. 205-211. 


\section{Dra. Abigail Casas-Muñoz}

Médico Pediatra, Maestra en Ciencias. Investigadora en la Coordinación de Estudios Avanzados sobre Maltrato Infantil - Prevención, Instituto Nacional de Pediatría. abycas_md@hotmail.com

Mtro. en Psic. Noé González-García Maestro en Psicología, Medicina Conductual. Colaborador en la Coordinación de Estudios Avanzados sobre Maltrato
Infantil-Prevención, Instituto Nacional de Pediatría. noegongar@gmail.com

\section{Dr. Arturo Loredo-Abdalá}

Médico Pediatra, Internista, Especialista en la atención integral del niño maltratado. Investigador en la Coordinación de Estudios Avanzados sobre Maltrato Infantil-Prevención, Instituto Nacional de Pediatría.

cainm_inp@hotmail.com

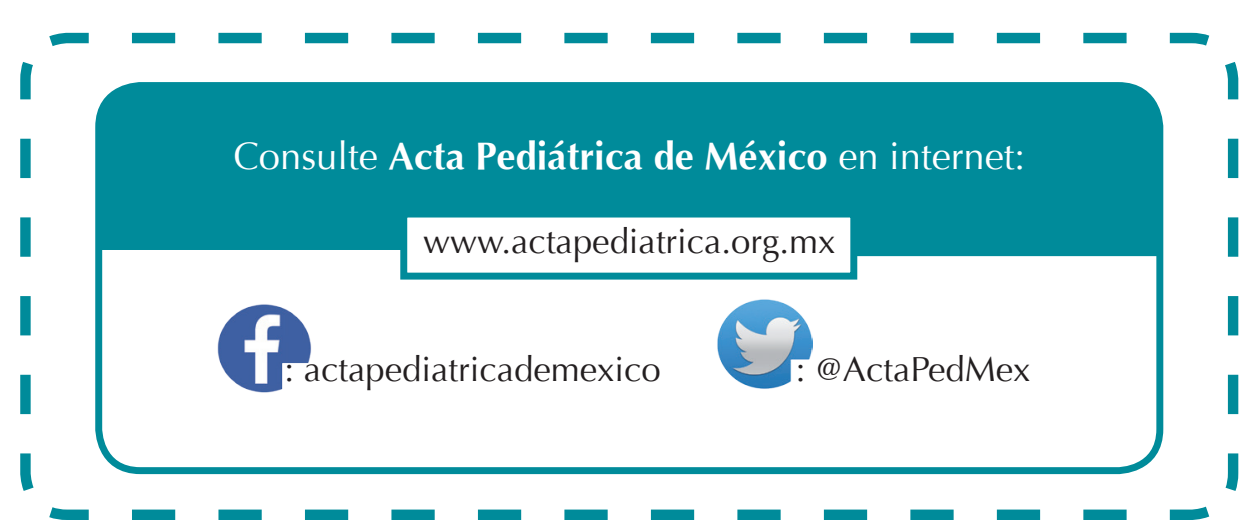

